\title{
Integration of subwavelength optical nanostructures for improved antireflection performance of mechanically flexible GaAs solar cells fabricated by epitaxial lift-off
}

*Xiaohan Li, Ping-Chun Li, Li Ji, Christopher Stender, Sudersena Rao Tatavarti,

Kimberly Sablon, and ${ }^{*}$ Edward T. Yu

Dr. X. H. Li, Dr. P. -C. Li, L. Ji, Prof. E. T. Yu

Microelectronics Research Center, The University of Texas at Austin

10100 Burnet Road, Austin, TX 78758, USA

*Email:xhli@utexas.edu; ety@ece.utexas.edu

Dr. C. Stender, Dr. S. R. Tatavarti

Microlink Devices, Inc.

6457 West Howard St., Niles, IL 60714, USA

Dr. K. Sablon

U. S. Army Research Laboratory

2800 Powder Mill Rd, Adelphi, MD 20783, USA

Keywords: antireflection, epitaxial lift-off, flexible, omnidirectional, solar cells

\begin{abstract}
We demonstrate the integration of subwavelength moth-eye and $\mathrm{Al}_{2} \mathrm{O}_{3}$ nanoisland structures fabricated on polymer packaging sheets and the surface of conventional $\mathrm{Al}_{2} \mathrm{O}_{3} / \mathrm{TiO}_{2}$ bilayer antireflection coatings, respectively, with epitaxial lift-off singlejunction GaAs solar cells. The mechanically flexible cell structure with the integrated optical nanostructures shows substantially improved photovoltaic performance under various incident angles and bending radii compared to devices without such structures: the increase in short-circuit current density arising from integration of these nanostructures ranges from $9 \%$ at normal incidence to $52 \%$ at $80^{\circ}$ incidence; and the reduction in short-circuit current density under moderate bending decreases from $9.7 \%$ to $6.7 \%$.
\end{abstract}




\section{INTRODUCTION}

The epitaxial lift-off (ELO) process, [1-3] which enables the separation of epitaxially grown thin-film device layers from their original growth substrates and reuse of growth substrates, can be employed to produce mechanically flexible, low-cost, light-weight, and high-efficiency GaAs thin-film solar cells. Since thin-film flexible ELO solar cells $[4,5]$ are likely to be deployed with illumination incident over a larger range of orientations, e.g. for applications such as mobile solar systems, [6,7] the need to reduce optical reflection loss of flexible ELO cells over a broad range of incident angles is greater compared to that of rigid cells. Conventional stacked planar thin-film antireflection coatings are only able to provide excellent antireflection performance at normal incidence and for small incident angles. [8] In order to achieve better broad-spectrum, omnidirectional antireflection performance, various approaches using subwavelength nanostructures have been reported. These can generally be grouped into two categories: nanostructures fabricated on substrates with high [9-11] and low [12-15] refractive indices. In prior work, the efficacy of such approaches has been demonstrated in fully packaged, rigid GaAs solar cells. [19] However, a complete demonstration of integrated nanostructures on commercial-grade, flexible ELO cells and with polymer packaging material for broadband, omnidirectional antireflection in photovoltaic applications has not been reported.

In this communication, we demonstrate the integration of a moth-eye textured polyethylene terephthalate (PET) packaging sheet combined with $\mathrm{Al}_{2} \mathrm{O}_{3}$ nanoisland structures on $1 \mathrm{~cm} \times 1 \mathrm{~cm}$ flexible ELO single-junction GaAs solar cells. A highthroughput, low-cost nanosphere lithography (NSL) process [16-20] is used to create 
moth-eye nanostructures and $\mathrm{Al}_{2} \mathrm{O}_{3}$ nanoislands on the PET packaging sheet surface and ELO GaAs cell surface, respectively. Measurements show that the ELO GaAs cell integrated with moth-eye textured PET packaging sheet and $\mathrm{Al}_{2} \mathrm{O}_{3}$ nanoislands exhibits greatly improved short-circuit current density $\left(J_{s c}\right)$ compared to the cell with conventional $\mathrm{Al}_{2} \mathrm{O}_{3} / \mathrm{TiO}_{2}$ bilayer antireflection coating and unpatterned PET packaging sheet over a wide range of incident angles: a $9 \%$ increase in $J_{s c}$ is observed at normal incidence, and a $52 \%$ increase in $J_{s c}$ is observed at $80^{\circ}$ angle of incidence. Current-voltage measurements reveal that the ELO cell integrated with a moth-eye textured PET packaging sheet and $\mathrm{Al}_{2} \mathrm{O}_{3}$ nanoislands shows a much less reduced $J_{s c}$ compared to the cell without optical nanostructures under a moderate bending condition: $9.7 \%$ reduction in $J_{s c}$ for the cell integrated with optical nanostructures in contrast with $6.7 \%$ reduction in $J_{s c}$ for the cell without optical nanostructures is observed. The self-cleaning properties of the moth-eye textured PET packaging sheet are evaluated by measuring the contact angle of water droplets on the sheet surface, which shows that the moth-eye textured PET packaging sheet has substantially improved self-cleaning property compared to the unpatterned PET packaging sheet.

\section{EXPERIMENT}

GaAs single junction solar cells were grown on GaAs (001) substrates by metallorganic chemical vapor deposition (MOCVD) at 100torr using Arsine $\left(\mathrm{AsH}_{3}\right)$, Phosphine $\left(\mathrm{PH}_{3}\right)$, Trimethylindium (TMI) and Trimethylgallium (TMG) as precursors with a V/III ratio > 50. The growth structure consisted of InGaP window and back surface field (BSF) layers, a $3.5 \mu \mathrm{m}$ GaAs base layer with $2 \times 10^{17} \mathrm{~cm}^{-3}$ p-type doping, a $0.1 \mu \mathrm{m}$ GaAs emitter with ntype doping in the range of $2 \times 10^{18} \mathrm{~cm}^{-3}$, and a $5 \mathrm{~nm}$ AlAs release layer. The epitaxial lift- 
off process was performed via a procedure similar to that reported elsewhere. [7] Currentvoltage characteristics were measured with HP4156A precision semiconductor parameter analyzer, using unpolarized normally incident light from a Newport Oriel 96000 solar simulator operating under irradiation intensity of $100 \mathrm{~mW} / \mathrm{cm}^{2}$ with an airmass (AM) $1.5 \mathrm{G}$ filter, and at a temperature of $25^{\circ} \mathrm{C}$. The irradiation intensity from the solar simulator was calibrated using a commercial-grade calibrated single-junction GaAs solar cell (Spire Corp. Lot\# 567-5-2). Photocurrent response spectra were measured at zero bias under unpolarized light from a single grating monochromator based system from Optronic Laboratories (OL750) with AC lock in detection with a chopping frequency of $188 \mathrm{~Hz}$. A calibration of the illumination intensity of the monochromator was performed using the calibrated single-junction GaAs solar cell (Spire Corp. Lot\# 567-5-2) with a reported spectral response. The PET packaging sheet is attached to the cell substrate using a space-grade encapsulant (Dow Corning 93-500, with a refractive index $\sim 1.41$ in the visible wavelength range). A home-made stretcher is used to bend the packaged flexible ELO GaAs cells.

Fig. 1a shows a schematic diagram of an ELO single-junction GaAs cell with conventional $\mathrm{Al}_{2} \mathrm{O}_{3} / \mathrm{TiO}_{2}$ bilayer antireflection coating integrated with $\mathrm{Al}_{2} \mathrm{O}_{3}$ nanoisland structure and combined with double-side textured PET packaging sheet, together with the refractive index profile. Fig. 1b-d show key steps in fabricating the moth-eye textured PET packaging sheet: $D_{l}=200 \mathrm{~nm}$ diameter polystyrene (PS) spheres were deposited on the PET packaging sheet surface using the NSL process (Fig. 1b), followed by reactiveion etchingwith $100 \mathrm{sccm}$ of oxygen at a pressure of $200 \mathrm{mT}$ Torr and radio frequency power of 100W for 4min (Fig. 1c), resulting in the moth-eye textured surface (Fig. 1d) with a 
nanostructure height $H_{1}=400 \mathrm{~nm}$. Fig. 1e-g show key steps in fabricating the $\mathrm{Al}_{2} \mathrm{O}_{3}$ nanoisland structure on ELO GaAs cell surface: $D_{2}=1000 \mathrm{~nm}$ PS spheres were deposited on the cell surface using the NSL process (Fig. 1e), followed by e-beam evaporation of 500nm $\mathrm{Al}_{2} \mathrm{O}_{3}$ (Fig. 1f); a lift-off process in toluene performed under sonication for $5 \mathrm{~s}$ completed the fabrication process for the $\mathrm{Al}_{2} \mathrm{O}_{3}$ nanoislands (Fig. 1g), with nanoisland height $H_{2} \sim 150 \mathrm{~nm}$. Scanning electron microscope (SEM) images of the fabricated motheye textured PET sheet surface and $\mathrm{Al}_{2} \mathrm{O}_{3}$ nanoisland array are shown in Fig. $\mathbf{1 h}$ and $\mathrm{i}$, respectively. With the gradual change in the refractive index at each key interface created by the double-side textured PET packaging sheet and $\mathrm{Al}_{2} \mathrm{O}_{3}$ nanoislands, the photovoltaic performance of the ELO GaAs cell is substantially improved over wide ranges of incident angles and wavelengths.

\section{RESULTS AND DISCUSSION}

Fig. 2a shows schematic diagrams of the three structures that are compared, including (i) ELO GaAs cell with conventional $\mathrm{Al}_{2} \mathrm{O}_{3} / \mathrm{TiO}_{2}$ bilayer antireflection coating integrated with unpatterned PET packaging sheet; (ii) ELO GaAs cell with conventional $\mathrm{Al}_{2} \mathrm{O}_{3} / \mathrm{TiO}_{2}$ bilayer antireflection coating integrated with double-side textured PET packaging sheet; and (iii) $\mathrm{ELO}$ GaAs cell with additional $\mathrm{Al}_{2} \mathrm{O}_{3}$ nanoisland structure (fabricated via NSL, using 1000nm diameter PS spheres) integrated with double-side textured PET packaging sheet. A photograph of the completely integrated flexible ELO GaAs cell is shown in Fig. 2b. Fig. 2c shows the measured $J_{s c}$ for devices of each type under different incident angles, in which $J_{s c}$ is calculated as the measured current value divided by the total cell area, $\sim 1.1 \mathrm{~cm}^{2}$. Compared to structure (i), structure (ii) shows a large improvement in $J_{s c}$ 
over the entire range of incident angles due to the moth-eye patterned PET packaging sheet surface, which greatly reduces the Fresnel reflection at the air/PET interface. Structure (iii) shows further improvement in $J_{s c}$ over the entire range of incident angles, which demonstrates the effectiveness of these integrated optical nanostructures in improving cells' photovoltaic performance over a broad range of incident angles. Fig. 2d shows the calculated $J_{s c}$ ratio of the fully integrated structure (iii) over that of structures (i) and (ii). A $9 \%$ increase in $J_{s c}$ is achieved for the completely integrated structure compared to structure (i) at normal incidence, while a $52 \%$ increase in $J_{s c}$ is observed at $80^{\circ}$ angle of incidence.

Fig. 3a-d show measured external quantum efficiency (E.Q.E.) for structures (i)-(iii), at incident angles of $0^{\circ}, 60^{\circ}, 70^{\circ}$, and $80^{\circ}$, in which the change in total illumination incident on the cell area at each incident angle is taken into account, so that E.Q.E. is calculated assuming that the incident light intensity does not change with varying the incident angle. In creating the $\mathrm{Al}_{2} \mathrm{O}_{3}$ nanoisland structures on devices studied in this set of measurements, we performed fabrication process steps essentially the same as those shown in Fig. 1e-g but with PS nanospheres $750 \mathrm{~nm}$ rather than $1000 \mathrm{~nm}$ in diameter, and subsequent deposition of $375 \mathrm{~nm}$ of $\mathrm{Al}_{2} \mathrm{O}_{3}$ rather than $500 \mathrm{~nm}$. Based on numerical calculation results reported in our earlier work, [19] it is found that for the $\mathrm{Al}_{2} \mathrm{O}_{3}$ nanoisland structure, the optimal photovoltaic performance is achieved with nanosphere diameters $\mathrm{D}_{2}$ greater than $500 \mathrm{~nm}$, and the photovoltaic performance differs very little for different values of $\mathrm{D}_{2}>$ $500 \mathrm{~nm}$.

Compared to structure (i) without optical nanostructures, structure (ii) shows overall improved antireflection performance over the entire range of incident angles, due to the 
reduced Fresnel reflection at the air/PET interface via the moth-eye textured structure. Note that at $80^{\circ}$ angle of incidence, structure (ii) shows slightly decreased E.Q.E. compared to structure (i) for wavelengths greater than $740 \mathrm{~nm}$, which we attribute to fabrication imperfections. Compared to structure (ii), structure (iii) shows very similar antireflection performance at incident angles of $0^{\circ}, 60^{\circ}$, and $70^{\circ}$, and further improved antireflection performance at $80^{\circ}$ angle of incidence, which demonstrates the effectiveness of our approach in improving flexible ELO cell efficiency over a broad range of incident angles.

Fig. 4a shows measured current-voltage characteristics for structures (i) and (iii) under AM1.5G, 1-sun illumination, under both flat and bent conditions. Flexible ELO cells were bent, using a home-made clipping apparatus, to a radius of curvature of $2.9 \mathrm{~cm}$, as shown in Fig. 4b. Structure (i) yields a $J_{s c}$ of $16.20 \mathrm{~mA} / \mathrm{cm}^{2}$ when flat, and $14.63 \mathrm{~mA} / \mathrm{cm}^{2}$ when bent, which is a $9.7 \%$ decrease in $J_{s c}$ from flat to bent condition. On the other hand, the structure (iii) yields a $J_{s c}$ of $18.14 \mathrm{~mA} / \mathrm{cm}^{2}$ at flat condition, and $16.92 \mathrm{~mA} / \mathrm{cm}^{2}$ at bent condition, which is a $6.7 \%$ decrease in $J_{s c}$ from flat to bent condition, smaller than that for structure (i) without optical nanostructures. In the computation of $J_{s c}$ for each measurement, we divide the measured total current by the original cell area. The improved $J_{s c}$ of structure (iii) under bent condition is attributed to the substantially improved transmission for TE polarized component of the incident light at larger incident angles. [19] The slightly reduced $V_{o c}$ values for structures (i) and (iii) are due to the reduction in photocurrent density under bent condition.

In real photovoltaic applications, cell efficiency also tends to degrade with the accumulation of dust and other contaminants on the cell surface, [21-24] which reduces 
the optical absorption efficiency. Various approaches have been studied to overcome this problem, including utilizing the hydrophobic characteristics of biomimetic surfaces. [2527] Our moth-eye textured PET packaging surface has hydrophobic properties comparable to those reported previously. [28,29] Photographs of a water droplet on a piece of moth-eye textured PET packaging sheet and unpatterned planar PET packaging sheet are shown in Fig. 5a and b, respectively. The water droplet on moth-eye textured PET packaging sheet has a contact angle $\sim 130^{\circ}$ with respect to the sheet surface, significantly larger than that of the unpatterned planar PET sheet, which has a contact angle of $\sim 64^{\circ}$. This observation suggests that in addition to the superior broadband, omnidirectional antireflection performance, self-cleaning behavior is another desirable attribute of the moth-eye textured PET packaging sheet.

\section{CONCLUSION}

In summary, we have demonstrated a highly effective antireflection strategy that can be readily implemented for flexible ELO GaAs solar cells, and that is able to substantially boost cell efficiency over broad ranges of incident angles and wavelengths. ELO GaAs solar cells fully integrated with moth-eye textured PET packaging sheet and $\mathrm{Al}_{2} \mathrm{O}_{3}$ nanoisland array structure are observed to yield $9 \%$ increase in $J_{s c}$ at normal incidence, and up to $52 \%$ increase in $J_{s c}$ at $80^{\circ}$ angle of incidence, compared to reference cells without the $\mathrm{Al}_{2} \mathrm{O}_{3}$ nanoisland structure combined with unpatterned PET packaging sheet. Current-voltage measurements show that the ELO cell fully integrated with optical nanostructures yields both higher absolute $J_{s c}$ value $\left(18.14 \mathrm{~mA} / \mathrm{cm}^{2}\right)$ at flat condition, and less reduced $J_{s c}$ when it is bent $\left(6.7 \%\right.$ reduction in $\left.J_{s c}\right)$, compared to those of the reference cell without optical nanostructures $\left(16.20 \mathrm{~mA} / \mathrm{cm}^{2}, 9.7 \%\right.$ reduction in $J_{s c}$ when bent). 
Moreover, superior self-cleaning properties of moth-eye textured PET packaging sheet aredemonstrated. With more advanced fabrication techniques, such as roll-to-roll nanoimprint lithography, [30-33] we anticipate that such approach can be employed for cells with much larger areas that are required for various photovoltaic applications.

\section{Acknowledgements}

Part of this work was supported by the U. S. Army Research Laboratory, the National Science Foundation (ECCS-1120832 and DMR-1311866), and the Judson S. Swearingen Regents Chair in Engineering at the University of Texas at Austin.

\section{REFERENCES}

[1] M. Konagai, M. Sugimoto, K. Takahashi, High efficiency GaAs thin film solar cells by peeled off technology, J. Cryst. Growth45 (1978) 277-280.

[2] R. Tatavarti, A. Wibowo, G. Martin, F. Tuminello, C. Youtsey, G. Hiller, N. Pan, M. W. Wanlass, M. Romero, InGaP/GaAs/InGaAs inverted metamorphic (IMM) solar cells on 4" epitaxial lifted off (ELO) wafers, $35^{\text {th }}$ IEEE PVSC Conference (2010) 002125-002128.

[3] J. J. Schermer, G. J. Bauhuis, P. Mulder, W. J. Meulemeesters, E. Haverkamp, M. M. A. J. Voncken, P. K. Larsen, High rate epitaxial lift-off of InGaP films from GaAs substrates, Appl. Phys. Lett. 76 (2000) 2131.

[4] G. J. Bauhuis, P. Mulder, E. J. Haverkamp, J. C. C. M. Huijben, J. J. Schermer, $26.1 \%$ thin-film GaAs solar cells using epitaxial lift-off, Sol. Energ. Mat. Sol. Cells 9 (2009) 1488-1491.

[5] K. Lee, J. D. Zimmerman, X. Xiao, K. Sun, S. R. Forrest, Reuse of GaAs substrates for epitaxial lift-off by employing protection layers, J. Appl. Phys.111 (2012) 033527. 
[6] K. M. Trautz, P. P. Jenkins, R. J. Walters, D. Scheiman, R. Hoheisel, R. Tatavarti, R. Chan, H. Miyamoto, J. G. J. Adams, V. C. Elarde, J. Grimsley, Mobile Solar Power. IEEE J. Photovolt. 3(1) (2013) 535-541.

[7] N. Pan, Epitaxial lift-off of large-area GaAs multi-junction solar cells for high efficiency clean and portable energy power generation, IEEE International Conference on Semiconductor Electronics (2014) 347-349.

[8] H. A. Macleod,Thin-Film Optical Filters, CRC Press, New York, 2010.

[9] H. Park, D. Shin, G. Kang, S. Baek, K. Kim, W. J. Padilla, Broadband optical antireflectionenhancement by integrating antireflective nanoislands with silicon nanoconical-frustum arrays, Adv. Mater. 23 (2011) 5796-5800.

[10] J. Y. Chen, M. H. Yu, S. F. Chang, K. W. Sun, Highly efficient poly (3,4ethylenedioxythiophene): poly (styrenesulfonate)/Si hybrid solar cells with imprinted nanopyramid structures, Appl. Phys. Lett. 103 (2013) 133901.

[11] Y. F. Huang, S. Chattopadhyay, Y. J. Jen, C. Y. Peng, T. A. Liu, Y. K. Hsu, C. L. Pan, H. C. Lo, C. H. Hsu, Y. H. Chang, C. S. Lee, K. H. Chen, L. C. Chen, Improved broadband and quasi-omnidirectional anti-reflection properties with biomimetic silicon nanostructures, Nature Nanotechnol. 2 (2007) 770-774.

[12] K. Choi, S. H. Park, Y. M. Song, Y. T. Lee, C. K. Hwangbo, H. Yang, H. S. Lee, Nano-tailoring the surfacestructure for the monolithic high-performance antireflection polymer film, Adv. Mater. 22 (2010) 3713-3718.

[13] K. C. Park, H. J. Choi, C. H. Chang, R. E. Cohen, G. H. McKinley, G. Barbastathis, Nanotextured silica surfaces with robust superhydrophobicity and omnidirectional broadband supertransmissivity, ACS Nano 6 (2012) 3789-3799.

[14] N. Yamada, T. Ijiro, E. Okamoto, K. Hayashi, H. Masuda, Characterization of antireflection moth-eye film on crystalline silicon photovoltaic module, Opt. Express 19 (2011) A118-A125.

[15] S. Chhajed, M. F. Schubert, J. K. Kim, E. F. Schubert, Nanostructured multilayer graded-index antireflection coating for Si solar cells with broadband and omnidirectional characteristics, Appl. Phys. Lett. 93 (2008) 251108.

[16] J. Rybczynski, U. Ebels, M. Giersig, Large-scale, 2D arrays of magnetic nanoparticles, Colloids and Surfaces A: Physicochemical and Engineering Aspects 219 (2003) 1-6.

[17] X. H. Li, P. -C. Li, D. Z. Hu, D. M. Schaadt, E. T. Yu, Light trapping in thin-film solar cells via scattering by nanostructured antireflection coatings, J. Appl. Phys. 114 (2013) 044310.

[18] X. H. Li, P. -C. Li, D. Z. Hu, D. M. Schaadt, E. T. Yu, Angular dependence of light trapping in $\operatorname{In}_{0.3} \mathrm{Ga}_{0.7} \mathrm{As} / \mathrm{GaAs}$ quantum-well solar cells, J. Appl. Phys. 115 (2014) 044303.

[19] X. H. Li, P. -C. Li, L. Ji, C. Stender, C. McPheeters, S. R. Tatavarti, K. Sablon, E. T. Yu, Subwavelength nanostructures integrated with polymer-packaged III/V solar cells for omnidirectional, broad-spectrum improvement of photovoltaic performance, Prog. Photovolt: Res. Appl. DOI: 10.1002/pip.2565 (2014).

[20] P. -C. Li, E. T. Yu, Large-area omnidirectional coating on low-index materials. J. Opt. Soc. Am. B 30 (2013) 2584-2588.

[21] J. Zhu, C. M. Hsu, Z. F. Yu, S. Fan, Y. Cui, Nanodome solar cells with efficient light management and self-cleaning, Nano Lett. 10(6) (2010) 1979-1984. 
[22] Y. B. Park, H. Im, M. Im, Y. K. Choi, Self-cleaning effect of highly waterrepellent microshell structures for solar cells, J. Mater. Chem. 21 (2011)633-636.

[23] L. K. Verma, M. Sakhuja, J. Son, A. J. Danner, H. Yang, H. C. Zeng, C. S. Bhatia, Self-cleaning and antireflective packaging glass for solar modules, Renew. Energ.36(9) (2011) 2489-2493.

[24] W. L. Min, B. Jiang, P. Jiang, Bioinspired self-cleaning antireflection coatings, Adv. Mater. 20 (2008) 3914-3918.

[25] S. A. Boden, D. M. Bagnall, Tunable reflection minima of nanostructured antireflective surfaces, Appl. Phys. Lett. 93 (2008) 133108.

[26] C. Chen, G. Hubbard, P. A. Shields, C. Liu, D. W. E. Allsopp, W. N. Wang, S. Abbott, Broadband moth-eye antireflection coatings fabricated by low-cost nanoimprinting, Appl. Phys. Lett. 94 (2009) 263118.

[27] J. H. Shin, K. S. Han, H. Lee, Anti-reflection and hydrophobic characteristics of M-PDMS based moth-eye nano-patterns on protection glass of photovoltaic systems, Prog. Photovolt: Res. Appl.19 (2011) 339-344.

[28] S. Nishimoto, B. Bhushan, Bioinspired self-cleaning surfaces with superhydrophobicity, superoleophobicity, and superhydrophilicity, RSC Adv. 6 (2013) 671-690.

[29] Y. R. Lin, H. P. Wang, C. A. Lin, J. H. He, Surface profile-controlled closepacked Si nanorod arrays for self-cleaning antireflection coatings, J. Appl. Phys. 106 (2009) 114310.

[30] S. H. Ahn, L. J. Guo, High-speed roll-to-roll nanoimprint lithography on flexible plastic substrates, Adv. Mater. 20 (2008) 2044-2049.

[31] M. G. Kang, M. S. Kim, J. Kim, L. J. Guo, Organic solar cells using nanoimprinted metal electrodes, Adv. Mater. 20 (2008) 4408-4413.

[32] X. Zhang, A. Hosseini, X. Lin, H. Subbaraman, R. T. Chen, Polymer-based hybrid-integrated photonic devices for silicon on-chip modulation and board-level optical interconnects, IEEE J. Sel. Topics Quantum Electron. 19 (2013) 196-210.

[33] S. Ahn, J. Cha, H. Myung, S. M. Kim, S. Kang, Continuous ultroviolet roll nanoimprinting process for replicating large-scale nano- and micropatterns, Appl. Phys. Lett. 89 (2006) 213101. 


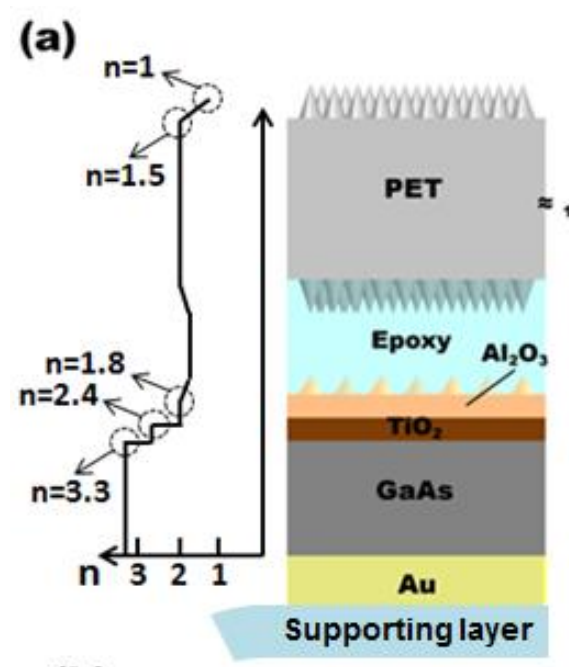

(h)

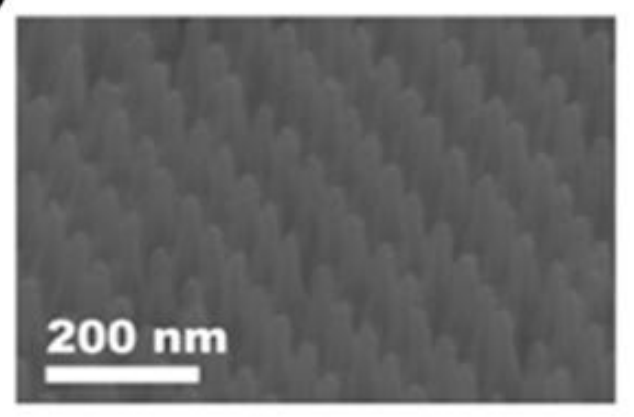

(b) $\quad D_{1} \quad$ (c)

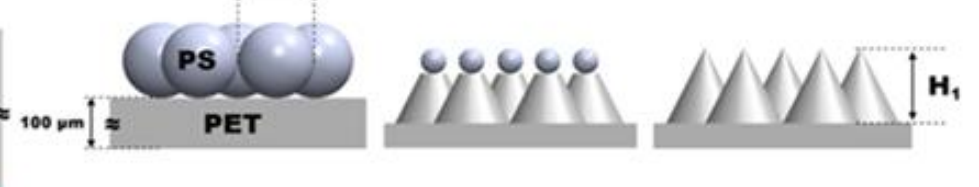

(e) $\stackrel{D_{2}}{\longrightarrow}$ (f)

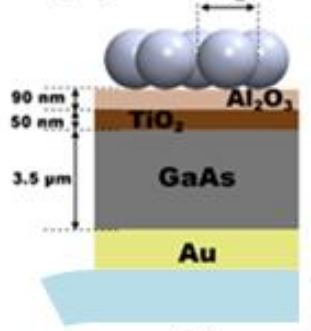

(i) (d)

(g)
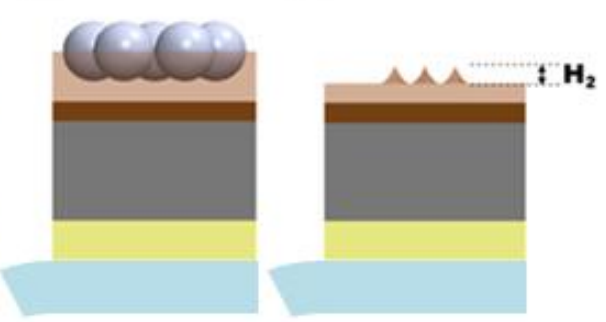

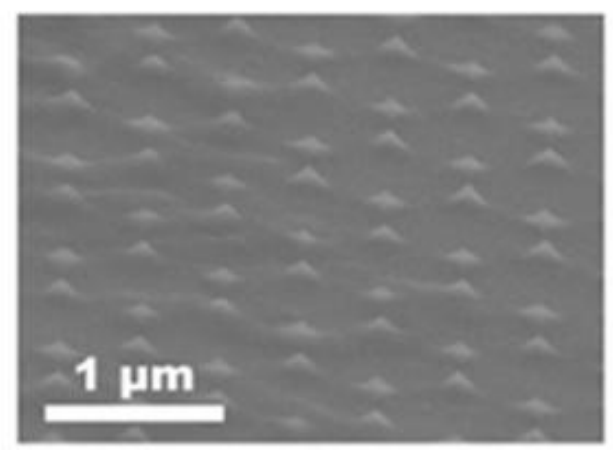

Fig. 1.(a) Schematic diagram of a polymer-packaged GaAs solar cell coated with conventional $\mathrm{Al}_{2} \mathrm{O}_{3} / \mathrm{TiO}_{2}$ bilayer antireflection coating with $\mathrm{Al}_{2} \mathrm{O}_{3}$ nanoislands and integrated with double-side moth-eye textured PET packaging sheet by space-grade encapsulant, together with the vertical refractive index profile. (b)-(d) Schematic diagrams of process flow for fabricating moth-eye structure on PET substrate using nanosphere lithography with polystyrene spheres (PS). (e)-(g) Schematic diagram of process flow for fabricating $\mathrm{Al}_{2} \mathrm{O}_{3}$ nanoislands structure on $\mathrm{Al}_{2} \mathrm{O}_{3} / \mathrm{TiO}_{2}$ bilayer 
antireflection coating. (h) SEM image of the completed moth-eye structure on PET substrate. (i) SEM image of the completed nanoislands structure.
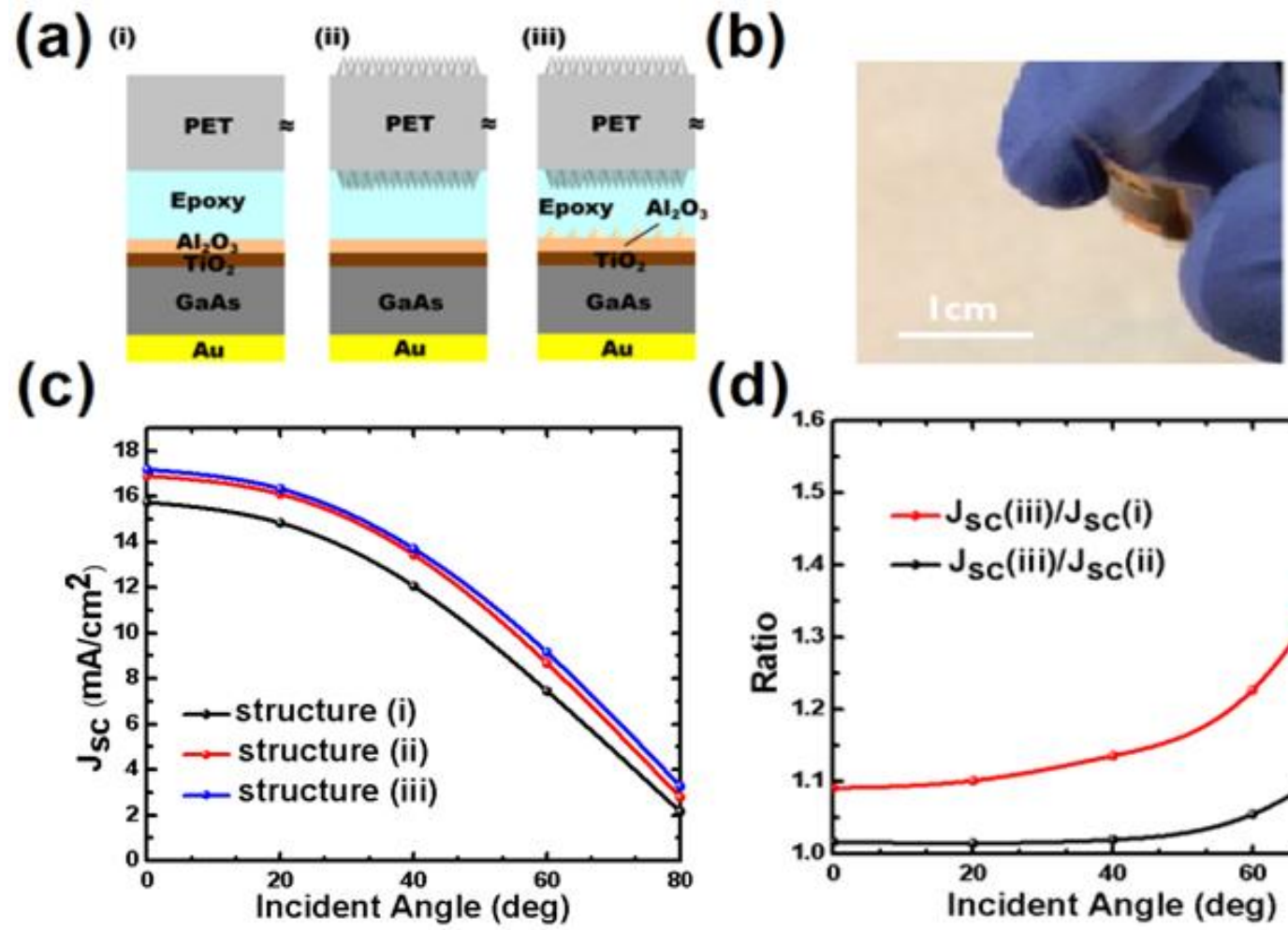

(d)

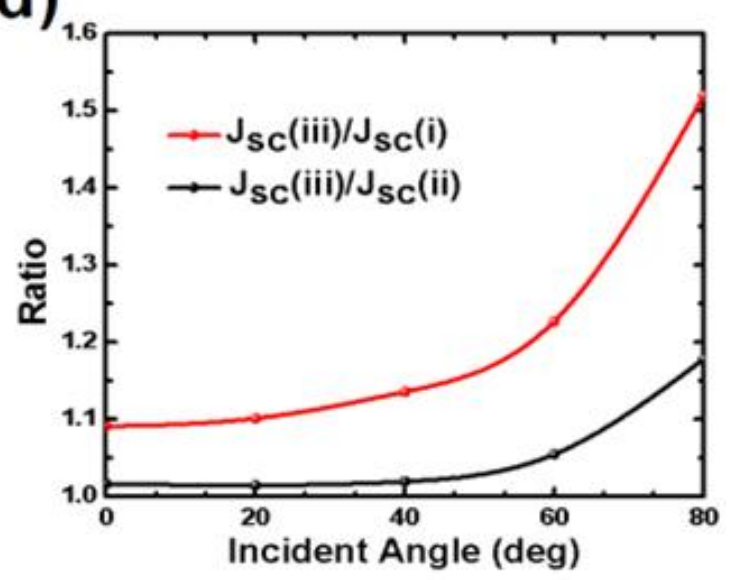

Fig.2. (a) Schematic diagrams of various integrated structures under comparison. (b) Photograph of ELO GaAs solar cell integrated with flexible PET packaging sheet. (c) Measured $J_{s c}$ for each integrated structure with incident angles varying from $0^{\circ}$ to $80^{\circ}$. (d) Calculated ratio for $J_{s c}$ of integrated structure (iii) over that of structures (i) and (ii). 
(a)
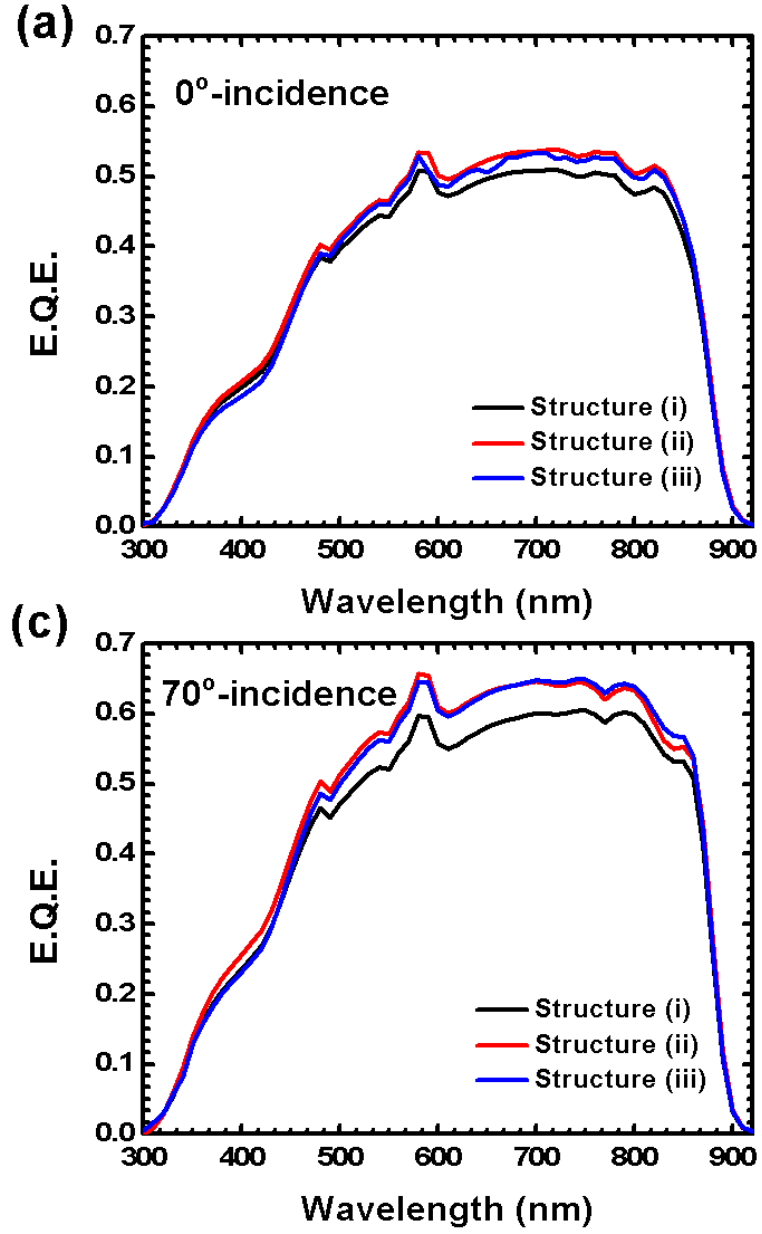

(b)

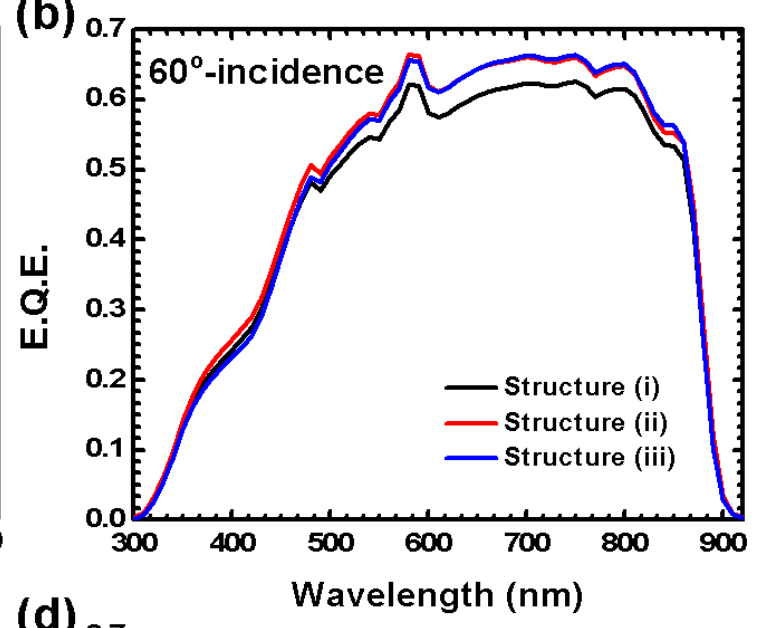

(d)

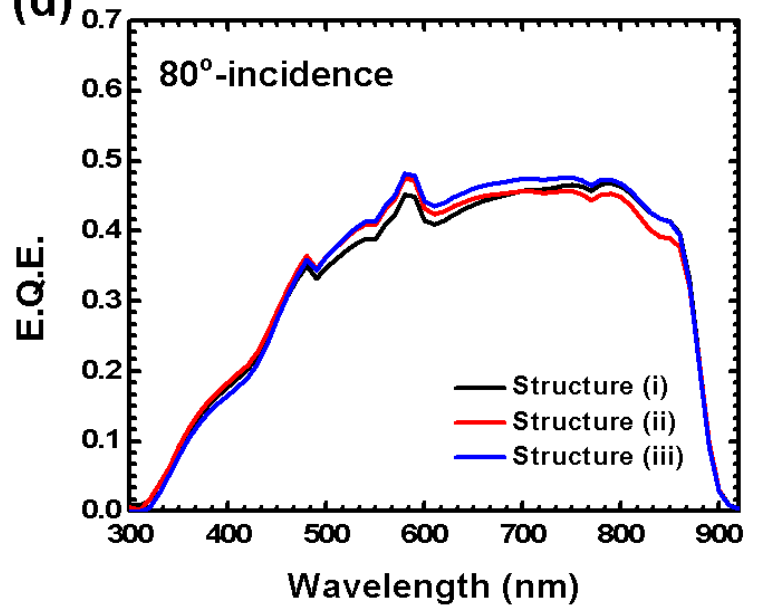

Fig.3. E.Q.E. measurements for structures (i)-(iii) at (a) $0^{\circ}$ angle of incidence; (b) $60^{\circ}$ angle of incidence; (c) $70^{\circ}$ angle of incidence; and (d) $80^{\circ}$ angle of incidence. 
(a)

(b)

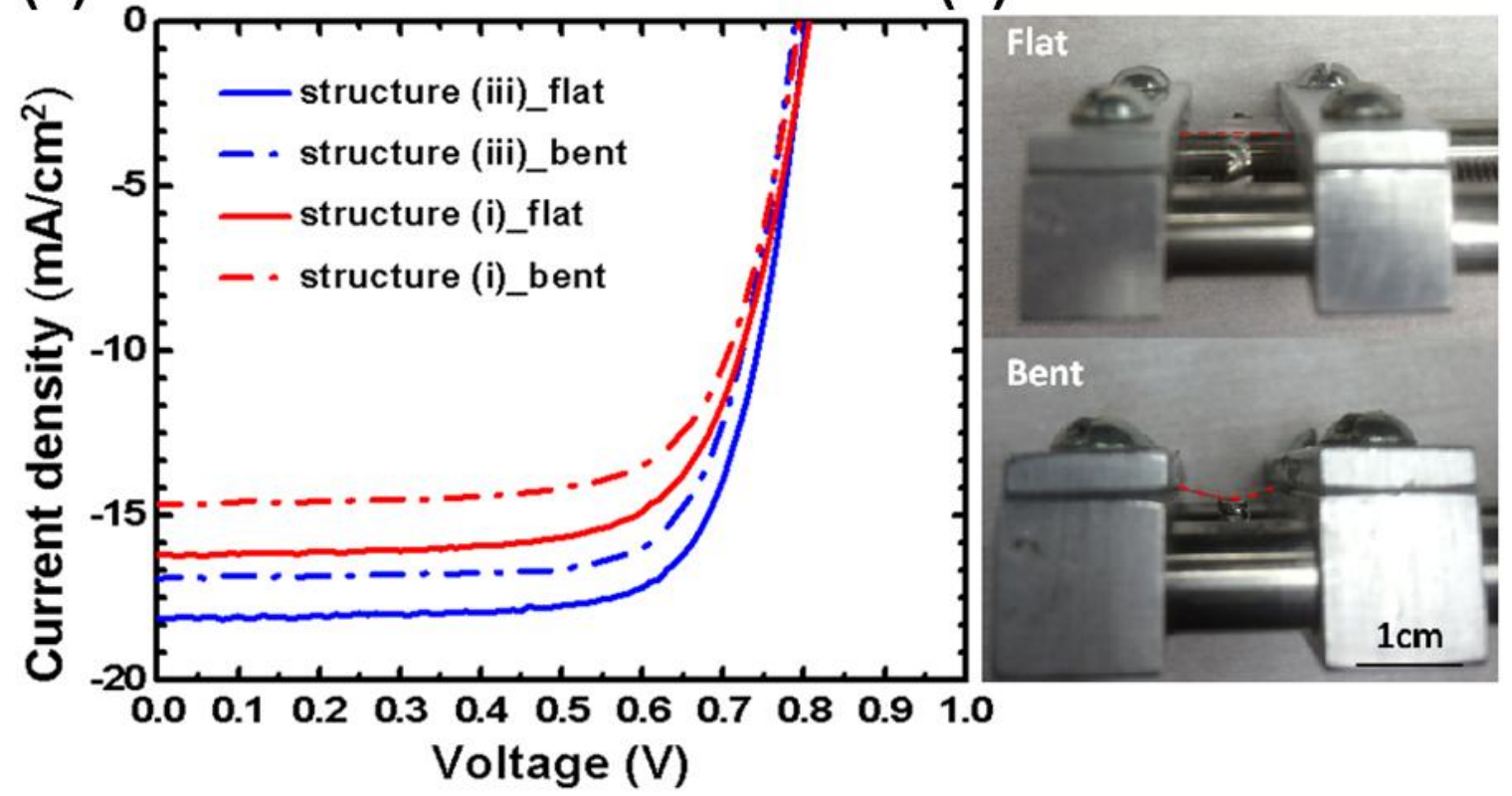

Fig.4. (a) Current - voltage characteristics for structures (i) and (iii) measured under flat and bent conditions under AM1.5G, 1-sun illumination. (b) Photographs of flexible ELO cells under flat and bent conditions. 


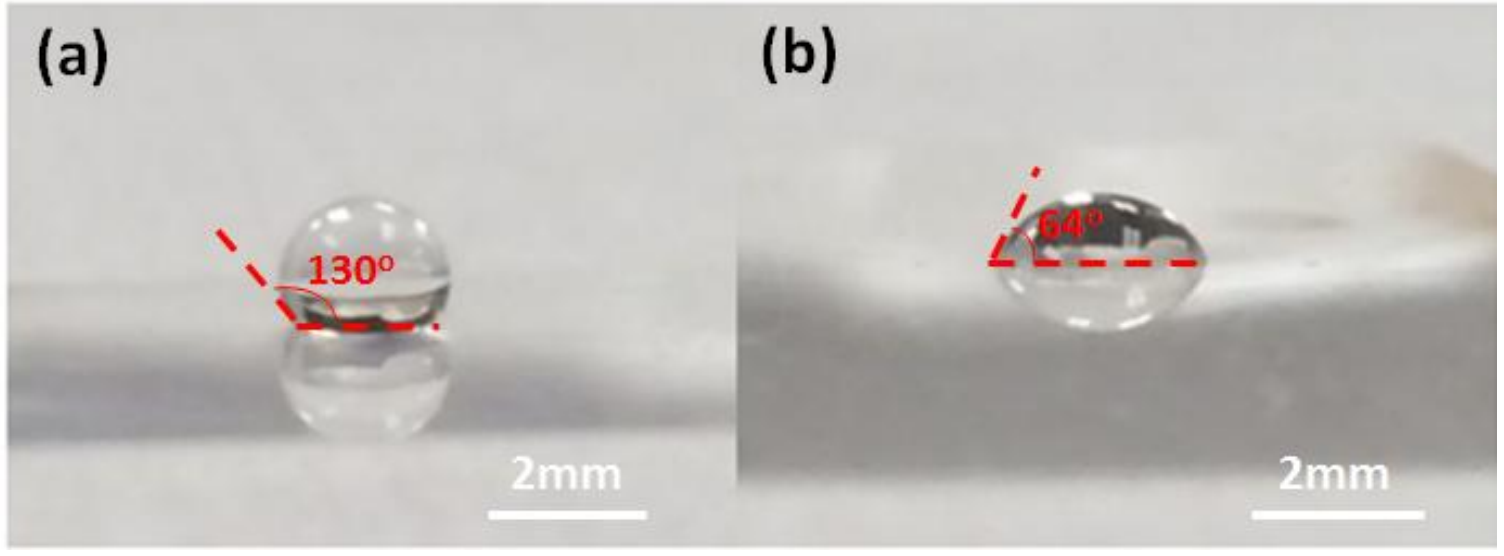

Fig.5. Photographs of a water droplet on (a) moth-eye textured PET packaging sheet, and (b) planar PET packaging sheet, along with the contact angles measured for each. 